\title{
Enhancing contraceptive usage by post-placental intrauterine contraceptive devices (PPIUCD) insertion with evaluation of safety, efficacy, and expulsion
}

\author{
Sahaja Kittur*, Y. M. Kabadi
}

Department of Obstetrics \& Gynecology, Karnataka Institute of Medical Sciences, Hubli-580022, Karnataka, India

Received: 27 November 2012

Accepted: 11 December 2012

*Correspondence:

Dr. Sahaja Kittur,

E-mail: drsahajakittur@rediffmail.com

\section{ABSTRACT}

Background: More than 100 million women in developing countries would prefer to avoid a pregnancy; but they may not be using any form of contraception. The study was conducted to assess the safety, incidence of perforation /pain/bleeding/foul discharge and expulsion rates at 6 week follow-up and willingness to continue when $\mathrm{Cu} \mathrm{T} 380 \mathrm{~A}$ inserted within ten minutes of placental expulsion both in vaginal and $\mathrm{C}$-section deliveries.

Methods: This was an open label, prospective, and longitudinal study. The study was approved by the ethics committee of FOGSI.

Results: The insertion of Intrauterine Contraceptive Devices (IUCD) at KIMS, Hubli was easy in $99.52 \%$ of subjects after normal delivery and $100 \%$ in all subjects after assisted vaginal deliveries. The position of the CuT was in situ in $94.78 \%$ of subjects, ultra sonogram was used in $24.76 \%$ to confirm location where threads were not visible in the vagina and in $6.19 \%$ of subjects the tip of IUCD was in the cervix which was pushed back into the uterus using artery forceps. It was expelled in $5.23 \%$ of patients. There was no case of perforation in this series and no other major complications.

Conclusions: Inserting CuT $380 \mathrm{~A}$ at 10 minutes after placental delivery is safe leading to the expanding of the usage of IUCD meeting the unmet needs. The expulsion rates would be minimal if it was inserted by a trained provider and placed at the fundus.

Keywords: Family planning, Contraception, Copper T, CuT 380 A, Expulsion

\section{INTRODUCTION}

More than 100 million women in developing countries would prefer to avoid a pregnancy; but they may not be using any form of contraception. Contraceptive prevalence is low in developing countries owing to unmet need for contraception. In India the unmet need is estimated to be $15.8 \%$ as estimated by DHS survey. ${ }^{1}$ Half of these women have no positive intention of using contraceptives but still wish to avoid pregnancy. There are multiple opportunities for the health personnel to interact with women during her reproductive cycle like antenatal, natal and postnatal period, and also during Immunization sessions at the Health Institutions and Village Health and nutrition days. Insertion of intra uterine contraceptive device (IUCD) at 10 minutes after delivery is appealing for several reasons:

(a) Recommencement of ovulation can be unpredictable after delivery, and the CuT provides exceedingly useful contraception during the puerperium. ${ }^{2}$

(b) The woman is also likely to have a high motivation for accepting contraception and the healthcare center provides a convenient setting for insertion of IUCD.

(c) In the developing countries, delivery may be the only time when a healthy woman comes into contact with health care providers and the chances of returning for contraceptive advice are uncertain. Family planning programs could use the opportunity of the antepartum 
period for counseling and immediate post-partum period for IUCD insertion for those who are willing. This would represent the segment with a scope for maximum promotion to curtail the fertility rates.

Most of the studies included in the Cochrane review in 2001, were conducted more than two decades ago- many of these IUCDs are no longer widely used, and two of the devices were never marketed. Nonetheless, up to now, these trials provide the available evidence on the safety and feasibility of inserting IUCDs immediately after childbirth $^{2,3}$ and it was considered that more research in these areas is needed. This is especially true since there are both advances and new understandings about IUCDs in terms of acceptability, low expulsion rates and cost effectiveness. Recent studies indicate that the expulsion rate is minimal if IUCD is inserted by the proper technique by a trained provider and is placed at the fundus, when inserted within ten minutes of placental expulsion in vaginal deliveries.

With this background, the present study was undertaken to assess the safety (incidence of perforation /pain/bleeding/foul discharge) and expulsion rates of $\mathrm{CuT}$ $380 \mathrm{~A}$, a long term reversible method that can serve as an alternative for sterilization for many women. Expulsion rates at 6 week follow up and willingness to continue when $\mathrm{Cu}$ T 380 A inserted within ten minutes of placental expulsion in vaginal deliveries. The acceptability of this method and the ease of insertion by trained personnel and the drop out rate for follow up were also assessed.

The current national strategy in India is for increasing IUCD uptake. The available target to cover with PPIUCD as a method of contraception has expanded in the recent past; since there is a 10 fold increase in women delivering in hospitals due to maternity benefit scheme. ${ }^{4}$ These women would now leave the hospital with a contraceptive in place, rather than being required to return for the IUCD insertion at a later date.

\section{METHODS}

\section{Study design}

This was an open label, prospective, and longitudinal study to assess the safety and efficacy of the $\mathrm{Cu}$ T $380 \mathrm{~A}$ when inserted within 10 minutes of placental expulsion.

\section{Patients}

Study participants were recruited through hospital antenatal clinics. Postpartum contraception was routinely discussed at prenatal visits.

All antenatal patients irrespective of maternal age, risk factors and proposed mode of delivery $\left(15^{\text {th }}\right.$ August 2010 to $15^{\text {th }}$ November 2010) at, KIMS, Hubli in Karnataka, India were counseled at their visits after 30 weeks of gestation on contraceptive options. Those willing for immediate postpartum insertion of $\mathrm{Cu} \mathrm{T} 380 \mathrm{~A}$ within 10 minutes of placental expulsion were included in the study group and informed consent was obtained. Those opting for insertion at 6 weeks / or permanent method of sterilization or other temporary methods were offered the same. The study was approved by the ethics committee of the Federation of Obstetric and Gynaecological Societies of India (FOGSI).

\section{Inclusion criteria}

All antenatal patients admitted at the center at around 36 to 40 weeks of gestation at our institution in India whose consent was obtained prior to admission were included. During enrollment the following criteria were considered for inclusion:

- $\quad 18$ - 40 years old

- 27 - 40 weeks EGA

- Desire to have CuT after counseling

- Anticipate vaginal delivery/C section

- No prior cesarean delivery

- No infections/ $\mathrm{Hb} \geq 8 \mathrm{~g} / \mathrm{dl}$

- No Diabetes Mellitus, Hypertension

- Oxytocin routinely/universally given after the delivery of the infant

\section{Exclusion criteria}

The patents with $<8 \mathrm{gm} \% \mathrm{Hb}$, with pelvic infection, fetal loss and following post-delivery complications were excluded:

- $\quad$ LSCS delivery

- $\quad$ Temperature $>38^{\circ} \mathrm{C}$ during or after labor

- $\mathrm{ROM}$ for $>24$ hours prior to delivery

- $\mathrm{PPH}$

\section{Method of insertion}

- Bimanual exam was performed to evaluate the cervix and the uterus after the delivery of the placenta and ensured empty cavity with contracted uterus.

- IUCD removed from insertion device and positioned at the edge of a sterile ring forceps/sponge holder.

- $\quad$ The copper T model Cu T 380 A (Figure 1) was inserted with all aseptic precautions within 10 minutes of placental expulsion with a sponge holder and fundal placement was ensured. String cut to the level of the cervix. The string was always visible at the cervix after the insertion. The IUCD was inserted under ultrasound guidance in the training period of three days to get the concept of placement at fundus and reinforced with palpation with hand at fundus. We were quite reassured that the USG ensured the placement which we could check with ease but later it gave us a confidence to place it even without the use of the USG machine subsequently. 


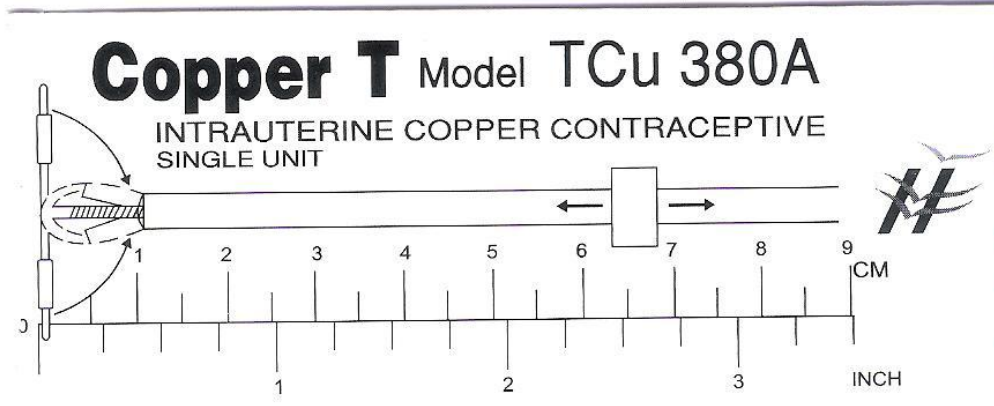

Each unit is wound with approximately $176 \mathrm{mg}$ of copper wire. In addition a swaged on each of the two transverse arms. Each coever on the device is $380 \pm 23 \mathrm{~mm}^{2}$ To be inserted in the uterus only by or under the supervision of physician. See detailed instructions for users. Administration : It is recommended that the unit be replaced by 10 years from the date of insertion.

Storage : Sto in Cool, Dry condition, Away from Sunlight. 63210 $\begin{array}{ll}\text { Mfg. Lic. Number 27/28/92 } & \text { Batch No. : } \\ \text { Sterilization by Gamma Radiation } & \text { Mfg. Date : JUL.2010 }\end{array}$ $\begin{array}{ll}\text { Sterilization by Gamma Radiation } & \text { Mfg. Date : JUL.2010 } \\ \text { Do not insert after the expiry date } & \text { Exp. Date : JUN.2015 }\end{array}$ CAUTION : Do not dispense without medical prescription. Insertion Instrument should not be reused and should be destroyed after use. Manufactured by HLL Lifecare Limited

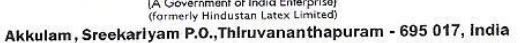

Figure 1: Copper T model CuT380.

\section{Safety analysis}

- Safety was assessed on the basis of patients' complaints with respect to excess of bleeding or foul discharge and pain if any.

- Complications such as perforation (if any) were noted.

\section{Follow up}

Follow up schedule was at 6 weeks after insertion and the following were assessed:

(a) Whether patient came in at the six week schedule

(b) The distance of stay of the hospital as an influencing factor for timely follow up

(c) If patient presented for earlier follow up because of pain/bleeding/fear/foul discharge/ demanding removal

(d) Willingness to continue the Cu IUCD as a method of contraception

The patients wanting removal of $\mathrm{Cu} \mathrm{T}$ were considered as discontinuations.

\section{Efficacy analysis}

Expulsion rates at 6 weeks follow-up were measured.

\section{Statistical analysis}

Paired Chi-square test was used for power calculation.

\section{RESULTS}

A total of 850 subjects were screened $\left(15^{\text {th }}\right.$ August 2010 to $15^{\text {th }}$ November 2010). Table 1 summarizes the relevant patients' demography and baseline characteristics of the 210 patients who were willing for PPIUCD insertion.
Table 1: Demographic characteristics of the subjects.

\begin{tabular}{|c|c|}
\hline \multicolumn{2}{|c|}{$\begin{array}{l}\text { Demographic characters and medical history of the } \\
\text { subjects, } N=210\end{array}$} \\
\hline Characteristics & $\mathbf{N}(\%)$ \\
\hline \multicolumn{2}{|l|}{ Age (y) } \\
\hline Min & 18 \\
\hline Max & 44 \\
\hline Mean & 23.75 \\
\hline \multicolumn{2}{|l|}{ Age Groups (y) } \\
\hline$<20$ & $08(3.80 \%)$ \\
\hline $20-25$ & $94(44.76 \%)$ \\
\hline $25-30$ & $68(32.38 \%)$ \\
\hline $30-35$ & $34(16.12 \%)$ \\
\hline$>35$ & $06(2.85 \%)$ \\
\hline \multicolumn{2}{|l|}{ Gestational Age (weeks) } \\
\hline Min & 36 \\
\hline Max & 42 \\
\hline Mean & 39 \\
\hline \multicolumn{2}{|l|}{ Education } \\
\hline College & $38(18.09 \%)$ \\
\hline School & $110(52.38 \%)$ \\
\hline Others & $10(4.76 \%)$ \\
\hline None & $52(24.76 \%)$ \\
\hline \multicolumn{2}{|l|}{ Distance of Stay $(\mathrm{km})$} \\
\hline Min & 02 \\
\hline $\operatorname{Max}$ & 150 \\
\hline Median & 76 \\
\hline \multicolumn{2}{|l|}{ History } \\
\hline Primi & $148(70.47 \%)$ \\
\hline Multipara & $62(29.53 \%)$ \\
\hline $\begin{array}{l}\text { Mean time for not ready to bear } \\
\text { children (yrs) }\end{array}$ & 3.04 \\
\hline
\end{tabular}




\section{Demography}

Marjory of the subjects $(44.76 \%)$ were aged between 2025 years, $52.38 \%$ of subjects had completed schooling and $49.64 \%$ of the subjects were residing $10-50 \mathrm{~km}$ close to the health care center. There were $70.47 \%$ (148) primiparas and $29.53 \%$ (62) multipara cases.

\section{Mode of delivery and ease of insertion}

Out of 210 enrolled, 201 (95.71\%) had normal vaginal delivery, $9(4.29 \%)$ assisted vaginal delivery. The insertion of IUCD was easy in $99.51 \%$ of subjects and no difficulties were reported. The insertion of IUCD was easy in $99.52 \%$ of subjects after normal delivery, and $100 \%$ in all subjects after assisted vaginal and c-section deliveries (Table 2).

Table 2: Mode of deliveries and Ease of insertion of CuT.

\begin{tabular}{|c|l|l|}
\multicolumn{3}{|c|}{$\begin{array}{c}\text { Mode of deliveries and Ease of insertion of CuT } \\
\text { N=210 }\end{array}$} \\
\hline & $\mathbf{N}=\mathbf{2 0 1}(\mathbf{\%})$ & $\mathbf{N = 0 9 ( \% )}$ \\
\hline Ease of insertion & $\begin{array}{l}\text { Normal } \\
\text { Delivery }\end{array}$ & $\begin{array}{l}\text { Assisted } \\
\text { Vaginal } \\
\text { Delivery }\end{array}$ \\
\hline Easy & $\begin{array}{l}200 \\
(99.76 \%)\end{array}$ & $09(100 \%)$ \\
\hline Complications & $00(00)$ & 00 \\
\hline \hline Difficult & $01(0.48 \%)$ & 00 \\
\hline
\end{tabular}

\section{Follow up and discontinuations}

Of 210 inserted, there were $3.80 \%$ cases reported no show for follow up. All the subjects were residing at a mean distance of 30 to $50 \mathrm{~km}$ from the PHC and majority of them had a scheduled follow up $(65.23 \%)$. Out of 202 cases of follow up, $21.90 \%$ had late follow up after being reminded by sending messages and calling them personally to their mobile numbers which was noted down when at the time of insertion and $4.28 \%$ of subjects had an early follow-up. In the early follow up group, majority of the subjects $(94.79 \%)$ reported nonspecific pain, $1.51 \%$ reported excess of bleeding and a small number of subjects $(1.08 \%)$ have had no complaints but had the fear for continuation.

\section{Expulsion and willingness to continue}

The position of the CuT was in situ in $84.76 \%$ of subjects, USG (ultrasonogram) was used in $24.76 \%$ to confirm location as the threads were curled up into the cervical canal and in $6.19 \%$ of subjects the limb of the IUCD was in the cervix which was pushed back into the uterine cavity using artery forceps.

Of these, $64 \%$ of subjects showed willingness to continue the IUCD, $2.82 \%$ of subjects expressed willingness for re-insertion if expelled and only $6.51 \%$ of subjects requested for removal of the IUCD (Table 3).
There was no case of perforation in this series and no other major complications. Four cases that had consented - IUCD not inserted because of perceived infection fever/foul discharge/prolonged leak. One case which reported early for follow-up was treated for perceived infection (pain/fever/foul discharge).

Table 3: Position of Cu T, Complaints, and Patient willingness.

\begin{tabular}{|l}
$\begin{array}{c}\text { Position of Cu T, Complaints, and Patient } \\
\text { willingness, N=210 (\%) }\end{array}$ \\
\begin{tabular}{|cl|} 
Ease of insertion & $209(99.52 \%)$ \\
\hline Easy & 00 \\
\hline Complications & $01(0.48 \%)$ \\
\hline difficult & $13(6.19 \%)$ \\
\hline Complaints & $92(43.80 \%)$ \\
\hline Excess of Bleeding & $105(50 \%)$ \\
\hline Pain & $09(4.28 \%)$ \\
\hline No Complaints & $46(21.90 \%)$ \\
\hline Follow-up Visit & $8(3.80 \%)$ \\
\hline Early & $137(65.23 \%)$ \\
\hline Late & $13(6.19 \%)$ \\
\hline No Show & $126(60 \%)$ \\
\hline Scheduled & $52(24.7 \%)$ \\
\hline In Cervix & $11(5.23 \%)$ \\
\hline In Situ (Checked clinically) \\
\hline In Situ USG \\
\hline Expelled & $16(7.61 \%)$ \\
\hline Position of CuT & $181(86.19 \%)$ \\
\hline Patient willingness & \\
\hline Patient's demand removal & \\
\hline Willing for continuation & \\
\hline Willing for re-insertion if & \\
\hline
\end{tabular} \\
\hline
\end{tabular}

\section{DISCUSSION}

The present trial was conducted to assess the safety and insertion related complications of IUCD insertion at 10 minutes after placental delivery in order to address unmet need for postpartum spacing methods. Providing the PPIUCD immediately following delivery presents a convenient opportunity for postpartum women to obtain a long acting method of contraception with the advantages of high motivation, assurance that the woman is not pregnant, and convenience and only a few contraindications to method. ${ }^{6}$ Acceptance for this method was $14 \%$ which indicates an expanded target group which is covered with IUCD as a contraceptive - a step towards diminishing the unmet need. Given the low rate of return for interval insertion, immediate placement may be preferable. $^{7}$ Though some studies have indicated that expulsion rates appear to be higher than with interval insertion - this is more applicable for developing 
countries where delivery may be the only time when a healthy woman comes into contact with health care providers and the chances of returning for contraceptive advice are uncertain.

Postpartum IUCD experience in $\mathrm{Egypt}^{8}$ shows that making things easy and convenient for women makes a big difference in ultimate acceptance. In their study, 1,024 women were counseled for immediate postpartum insertion of IUCD. Of those who agreed for immediate insertion, $71.2 \%$ had the IUCD inserted. Those who decided to come back later, only $7.2 \%$ had got it inserted. In yet another study from Columbia, 95\% women expressing a desire for immediate post-partum IUCD insertion had it done. In contrast, only $45 \%$ of them wishing later insertion ultimately had an IUCD inserted. While some of the latter group may have been ambivalent and later decided against the IUCD, the inconvenience and expense of a return visit probably deterred a few subjects. ${ }^{9}$ Similarly, in the Ankara study- $89 \%$ women planned to start family planning within 6 months, however only $52 \%$ did so at 6 months. ${ }^{10}$ In our study, $14 \%$ were willing and of these, all underwent PPIUCD insertion, and none changed their mind at delivery. A significant percentage of these would have perhaps not turned up later and it would have been a lost opportunity to cover these women under some reliable form of contraception.

The popularity of immediate post-partum IUCD insertion in countries as diverse as China, Mexico, and Egypt support the feasibility of this approach. ${ }^{11}$

In the present study the insertion of IUCD was easy in $>99 \%$ of subjects in normal and assisted deliveries at 10 minutes after post-partum with approximately 5\% expulsion rates. Immediate post-partum IUCD insertion is common in many countries like China, Mexico, and Egypt. $^{12-14}$ No studies reported inference of CuT with lactation. ${ }^{15-17}$ Post-placental insertion appears to be a convenient approach to IUCD initiation, with no observed increase in the incidence of excessive bleeding or endometritis. ${ }^{18}$ Clinical experience in these diverse settings admits the practicality of this approach. When a copper $\mathrm{T}$ device is inserted post-placentally or immediately postpartum by an experienced and trained clinician the expected expulsion rates could be $7-15 \%$ at six months. ${ }^{19}$ From systematic reviews, increase in expulsion rates occurred with delayed postpartum insertion when compared to immediate insertion and with immediate insertion when compared to interval insertion. Post-placental placements during cesarean delivery are associated with lower expulsion rates than post-placental vaginal insertions, without increasing rates of postoperative complications. ${ }^{6}$ Postpartum IUCD insertion is still highly effective \& beneficial, for all timing categories; MEC/SPR Revision Meeting, 4-08, WHO Systematic Review of Timing of Postpartum IUCDs: states "Immediate post-placental insertion ( $<10 \mathrm{~min})$ appears to decrease the risk for expulsion compared to other postpartum time intervals, although immediate insertion carries a higher risk of expulsion compared to interval insertions". It is also known that expulsion rates can be reduced by placing it high in uterine fundus, by trained/skilled provider. Postpartum insertion in Turkey ${ }^{22}$ on $74 \%$ vaginal deliveries, $26 \%$ cesarean deliveries with $94 \%$ at 6 weeks, $89 \%$ at 6 months, $78 \%$ at 12 months had a 1-year cumulative expulsion rate: $12.3 \%$ and continuation rates: $87.6 \%$ at 6 months, $76.3 \%$ at 12 months. This proves that it is imperative to remember that the success of IUCD insertions involve well trained providers who exhibit: good clinical judgment in selecting acceptors, care, sensitivity, and thoroughness in informing the user about IUCDs and common side effects, skill in inserting the IUCD, Knowledge of and ability to recognize current or potential problems, ability to take clinical action for these problems, including knowing when and where to refer subjects with serious complications. ${ }^{23}$ The key component of this study was the three day training program and the insertions being done only by these trained providers and not the other senior/junior order provider in the unit/department. The expulsion rates in trials of immediate post-partum insertion generally appear lower than those reported with delayed post-partum insertions. ${ }^{21}$ After clinical examination, the position of the IUCD was in situ in $97.61 \%$ of subjects.

The successes of IUCD programs require a scheduled follow-up ideally three to six weeks, but not later than three months, for their first check up. Thereafter, there is no need for a fixed follow-up schedule. Nearly $80 \%$ of the patients followed up on schedule of six weeks. The discontinuation (no show) rates due to other reasons were $8.60 \%$ and re-insertion rates were $2.82 \%$ which were lower and comparable to other studies. Reminder phone calls were made and on occasions, transport provided and also an incentive given at the follow up visit at both the centers. This ensured the success of nearly $90 \%$ followup.

Majority of the subjects $(86.19 \%)$ showed willingness for continuation of IUCD and only a less number $(7.61 \%)$ requested removal most of them were due to family pressure from husband and in laws after they came to know about the insertion. Early follow-up may be important in identifying spontaneous IUCD expulsions. The failure rates of the IUCD leading to the pregnancy were not reported in our study since the follow up was only until six weeks. Other trials reported pregnancy rates ranged from 0 to $2 \%$, which compares favorably with the estimated failure rates for IUCDs of 0.1 to $0.8 \% .^{24}$ According to UN 1997, CuT 380 A confers contraceptive protection similar to that achieved with tubal sterilization. $^{25,26}$

Overall, immediate post-partum insertion of IUCD appears safe and effective. The evidence suggests that immediate post-placental insertion of CuT 380 models is 
an effective, useful, safe, convenient and low-cost procedure for early postpartum contraception. ${ }^{27}$

\section{CONCLUSION}

Inserting $\mathrm{CuT} 380 \mathrm{~A}$ at 10 minutes after placental delivery is safe leading to the expanding of the usage of IUCD meeting the unmet needs. The expulsion rates would be minimal if it is inserted by a trained provider and placed at the fundus. It is safe, convenient, cost effective, reversible and long term birth spacing method. It should be part of a maternal/newborn/reproductive health package. The government schemes like Janani Suraksha Yojana (JSY) is an opportunity to add PPIUCD into family planning program and could address the high unmet need for Family planning in India.

\section{ACKNOWLEDGEMENTS}

We extend our sincere thanks to Dharwad district health office for providing all $\mathrm{Cu}-380 \mathrm{~A}$ devices free of cost.

\section{REFERENCES}

1. Klijzing E. Are there unmet family planning needs in Europe? Fam Plann Perspect 2000;32:74-81.

2. Grimes DA, Lopez LM, Schulz KF, van Vliet HA, Stanwood NL. Immediate post-partum insertion of intrauterine devices. Cochrane Database Syst Rev 2010;(5):CD003036.doi:10.1002/14651858.CD0030 36.

3. Grimes D, Schulz K, van Vliet H, Stanwood N. Immediate post-partum insertion of intrauterine devices. Cochrane Database Syst Rev 2001;(2):CD003036.

4. National Rural Health Mission Ministry of Health \& Family Welfare Government of India. JSY. Available at http://www.mohfw.nic.in/layout_0906.pdf. Accessed 19 September 2012.

5. O'Hanley K, Huber DH. Postpartum IUCDs: keys for success. Contraception 1992;45:351-61.

6. Amy JJ, Tripathi V. Contraception for women: an evidence based overview. BMJ 2009;339:b2895.

7. Fox MC, Oat-Judge J, Severson K, Jamshidi RM, Singh RH, McDonald-Mosley R, Burke AE. Immediate placement of intrauterine devices after first and second trimester pregnancy termination. Contraception 2011;83:34-40.

8. Mohamed SA, Kamel MA, Shaaban OM, Salem HT. Acceptability for the use of postpartum intrauterine contraceptive devices: Assiut experience. Med Princ Pract 2003;12:170-5.

9. Echeverry G. Family planning in the immediate postpartum period. Stud Fam Plann 1973;4:33-5.

10. Pile JM et al. Providing family planning services to abortion clients: Lessons learned in Turkey, paper presented at annual meeting of the American Public health Association, San Diego, CA, Oct. 29-Nov.2, 1995 .
11. Grimes D, Schulz K, Van Vliet H, Stanwood N. Immediate post-partum insertion of intrauterine devices. Cochrane Database Syst Rev 2003;(1):CD003036.

12. Morán C, Fuentes G, Amado F, Higareda H, Bailón $\mathrm{R}$, Zárate A. Postpartum contraceptive practice in hospitals of the Federal District. Salud Publica Mex 1992;34:18-24.

13. Morrison C, Waszak C, Katz K, Diabate F, Mate EM. Clinical out-comes of two early postpartum IUCD insertion programs in Africa. Contraception 1996;53:17-21

14. $\mathrm{Xu}$ JX, Reusche C, Burdan A. Immediate postplacental insertion of the intrauterine device: a review of Chinese and the world's experiences. Adv Contracept 1994;10:71-82.

15. Diaz S, Croxatto HB. Contraception in lactating women. Curr Opin Obstet Gynecol 1993;5:815-22.

16. Diaz S, Zepeda A, Maturana X, Reyes MV, Miranda $\mathrm{P}$, Casado ME, et al. Fertility regulation in nursing women. IX. Contraceptive performance, duration of lactation, infant growth, and bleeding patterns during use of progesterone vaginal rings, progestinonly pills, Norplant implants, and Copper T 380-A intrauterine devices. Contraception 1997;56:223-32.

17. Zacharias S, Aguilera E, Assenzo JR, Zanartu J. Effects of hormonal and nonhormonal contraceptives on lactation and incidence of pregnancy. Contraception 1986;33:203-13.

18. Welkovic S, Costa LO, Faúndes A, de Alencar Ximenes R, Costa CF. Post-partum bleeding and infection after post-placental IUCD insertion. Contraception 2001;63:155-8.

19. O'Hanley K, Huber DH. Postpartum IUCDs: Keys for success. Contraception 1992;45:351-61.

20. Echeverry G. Family planning in the immediate postpartum period. Stud Fam Plann 1973;4:33-5.

21. Chi IC, Farr G. Postpartum IUD contraception--a review of an international experience. Adv Contracept 1989;5:127-46.

22. Celen S, Möröy P, Sucak A, Aktulay A, Danişman N. Clinical outcomes of early postplacental insertion of intrauterine contraceptive devices. Contraception 2004;69:279-82.

23. The Population Council and the Program for Appropriate Technology in Health (PATH). The Copper T 380A IUCD: A Manual for Clinicians. 2nd ed. Seattle, Washington: PATH, 1989.

24. Trussell J. Contraceptive failure in the United States. Contraception 2004;70:89-96.

25. United Nations Development Programme/UN Population Fund/WHO/World Bank, Special Programme of Research, Development and Research Training in human Reproduction. Longterm reversible contraception. Twelve years of experience with the TCu380A and TCu220C. Contraception 1997;56:341-52.

26. Peterson HB, Xia Z, Hughes JM, Wilcox LS, Tylor LR, Trussell J. The risk of pregnancy after tubal sterilization: findings from the U.S. Collaborative 
Review of Sterilization. Am J Obstet Gynecol 1996;174:1161-8.

27. Celen S, Möröy P, Sucak A, Aktulay A, Danişman N. Clinical outcomes of early postplacental insertion of intrauterine contraceptive devices. Contraception 2004;69:279-82.

DOI: $10.5455 / 2320-1770 . i j r \operatorname{cog} 001112$

Cite this article as: Kittur S, Kabadi YM. Enhancing contraceptive usage by post-placental intrauterine contraceptive devices (PPIUCD) insertion with evaluation of safety, efficacy, and expulsion. Int J Reprod Contracept Obstet Gynecol 2012;1:26-32. 